\title{
Dietary restraint, dietary disinhibition and susceptibility to hunger of normal weight and overweight women
}

\author{
Elizabethe A. Esteves ${ }^{\mathrm{a}, *}$, Maura Oliveira Costa ${ }^{\mathrm{b}}$, Lauane Gomes Moreno ${ }^{\mathrm{b}}$, \\ Ana Maria F. Viana ${ }^{b}$, Andrea Carvalho Cabral ${ }^{c}$, and Josefina Bressan ${ }^{d}$ \\ ${ }^{a}$ Assistant Professor, Department of Nutrition, Federal University of Vales do Jequitinhonha e Mucuri, Diamantina, Minas \\ Gerais, Brazil \\ ${ }^{\mathrm{b} N u t r i t i o n i s t ~ b y ~ F e d e r a l ~ U n i v e r s i t y ~ o f ~ V a l e s ~ d o ~ J e q u i t i n h o n h a ~ e ~ M u c u r i, ~ M i n a s ~ G e r a i s, ~ B r a z i l ~}$ \\ 'Nutritionist by Federal University of Viçosa, Viçosa, Minas Gerais, Brazil \\ ${ }^{\mathrm{d}}$ Associate Professor at Department of Nutrition and Health, Federal University of Viçosa, Viçosa, Minas Gerais, Brazil
}

Received August 16, 2011; accepted November 29, 2011

\section{KEYWORDS \\ Eating behavior; \\ Restraint; \\ Disinhibition; \\ Hunger; \\ Body weight; \\ Body composition}

\begin{abstract}
Background: Eating behavior is a strong predictor of weight gain in adults. Research characterizing differences in components of dietary restraint, disinhibition and hunger between overweight and normal weight subjects is insufficient.

Objective: To evaluate and to compare scores of dietary restraint (DR), disinhibition $(\mathrm{DD})$, and hunger $(\mathrm{H})$ between women at normal weight (NW, $\mathrm{n}=32$ ) and overweight (WW, $\mathrm{n}=32$ ). We evaluated correlations between these scores with adiposity and food intake variables. Material and methods: It was a cross-sectional comparison of two groups (overweight and normal weight women), at ages between 20 and 40 years. We measured body mass index (BMI), waist circumference (WC), body composition (BC), energy and macronutrient intake (EMI), DR, DD and $\mathrm{H}$. The differences between groups were analyzed using Student's T or Mann-Whitney tests. Correlations among DR, DD or H and all other variables in each group were also evaluated.

Results: Mean values of BMI, CC, BC, EMI, DR, DD and $\mathrm{H}$ were higher for WW $(P<.05)$. Half or more of WW women had moderate or high levels of DR, DD or $\mathrm{H}$. Mean scores of these variables were higher for this group $(P<.05)$ and tended to "high level". There was a positive correlation between the $\mathrm{H}$ and the EMI $(P<.05)$ in the WW group.

Conclusions: Eating behavior was associated with weight and body composition in these women, especially for WW. Strategies that address changes in cognitive control of food intake can become useful tools in controlling body weight.

(c) 2011 Asociación Española de Dietistas-Nutricionistas. Published by Elsevier España, S.L. All rights reserved.
\end{abstract}

\footnotetext{
*Corresponding author.

E-mail: eaesteves@yahoo.com.br (E.A. Esteves).
} 


PALABRAS CLAVE
Comportamiento
alimentario;
Restricción;
Desinhibición;
Hambre;
Peso corporal;
Composición corporal

\section{Introduction}

Obesity is the excessive accumulation of body fat in a quantity that is harmful to human health. The accumulation of body weight (fat) can cause numerous health hazards such as cardiovascular disease, non-insulin dependent diabetes mellitus, dyslipidemia, hypertension, insulin resistance, hepatobiliary disease, cancer, osteoarthritis, stroke and lung diseases ${ }^{1}$. Thus, the elucidation of how common strategies of weight control can be associated with body mass index (BMI) is essential in combating the disease ${ }^{2}$.

Hays et $\mathrm{al}^{3}$ and Drapeau et $\mathrm{al}^{4}$ have demonstrated that eating behaviour is a strong predictor of weight gain in adults, in contrast to the controversial predictive values of other variables involved, such as diet composition and the percentage of energy derived from lipids, carbohydrates and proteins. Three well-known types of behaviour are called "dietary disinhibition", "dietary restraint" and "hunger", which are commonly assessed using a psychometric questionnaire developed by Stunkard and Messick ${ }^{5}$.

According to these authors, dietary restraint refers to the perception that the individual has to monitor and to strain for limiting the intake in order to maintain the body weight. It represents the cognitive control of eating behaviour, in contrast to the physiological control, such as hunger and satiety. Dietary disinhibition refers to the susceptibility to eating by loosing self-control. It is also associated with the desire to control body weight, considering that this variable would prevent the efforts for losing weight ${ }^{5}$. Hunger is the susceptibility to eat in response to perceived physiological symptoms that signal the need for food ${ }^{6}$.

It is known that women tend to do all sorts of diets for losing weight, intentionally restricting the dietary intake for this purpose. On the other hand, people who control their eating habits are often tempted to lose control of such habits ${ }^{7}$. In this situation, individuals on dietary restriction can ingest more calories than those who are not on dietary restraint. There are several studies that support this hypothesis $^{7-10}$.

However, studies with both women and men have shown no consistent associations between the restraint or hunger with $\mathrm{BMI}$, whereas disinhibition has been strongly associated with that index ${ }^{2,4,11,12}$. Also, most of these studies have been conducted in individuals who were enrolled in controlled weight loss interventions and not in a "real-life" uncontrolled context. Additionally, the prevalence of overweight and obesity in older women is steadily rising in many developing countries, hence it is important to identify eating behaviour components and differences or adaptations between younger individuals at normal weight or overweight that can become useful tools in controlling body weight. These strategies could help to maintain a healthy body weight with advancing age.

In this context, the objectives of this study were: a) to evaluate and compare the levels of dietary restraint (DR), dietary disinhibition (DD) and susceptibility to hunger $(\mathrm{H})$ between normal and overweight adult women, and $b$ ) to assess the correlation between these scores with adiposity parameters and food intake of these women. 


\section{Material and methods}

It was conducted a cross-sectional study with adult women (20 to 40 years) living in a city in Minas Gerais state, Brazil. Overweight volunteers were screened and selected from a waiting list of a School Nutrition Clinic. Normal weight women were recruited through the divulgation of posters and advertisements distributed at commercial city's points. From the screening and recruitment, potential volunteers were contacted and the research was presented to them. The inclusion criteria were evaluated for those who have expressed interest in participating in the study.

For participation in the study, volunteers had to meet the following criteria: being female, Body Mass Index (BMI) between 18.5 and 29.9, aged 20 to 40 years, good health condition, non smoking, do not using drugs that could interfere with energy expenditure or food intake, not pregnant or lactating and should not be on dietary treatment for losing weight at the time of the study.

The selected subjects were divided into two groups: normal weight (NW) ( $\mathrm{n}=32$; $\mathrm{BMl}$ between 18.5 and 24.9), and overweight (OW) $\left(n=32\right.$; BMI between 25 and 29.9) ${ }^{13}$. The total number of volunteers for each group was based on the number of overweight volunteers who was waiting for treatment in the nutrition school's clinic for more than a month and who agreed to participate in the study.

A structured questionnaire was used for collecting personal data. It contained information such as educational level, alcohol intake, physical activity, weight changes over the past three months, personal history of disease and family history of related diseases to inadequate nutrition (diabetes mellitus, hypertension and dyslipidemia), among others.

The BMI was verified by taking measurements of height and weight through Quetelet equation $(\mathrm{BMI}=$ weight in kilograms/height ${ }^{2}$ in meters), by means standard procedures. The volunteers were classified as normal weight or overweight according to World Health Organization ${ }^{13}$. Waist circumference (WC) was measured as described by $\mathrm{WHO}^{13}$.

The percentage of body fat (\% BF) and percentage of lean mass (\% LM) were determined by tetra polar electrical bioimpedance analysis (Byodinamics ${ }^{\circledR}, 410$ ), according to the manufacturer procedures. The volunteers were instructed in advance regarding the requirements for testing, as described by Lukaski et al ${ }^{14}$.

Three food records were used on alternate days in the same week and a day in the weekend, as suggested by Willett and Stampfer ${ }^{15}$, to access the energy and macronutrient intake. The volunteers were instructed to make a record of all eaten foods during this period using household measures. They received directions regarding portioning and cooking measures. Records were reviewed, individually, with all volunteers. Data obtained were transformed into weight $(\mathrm{g})$ or volume $(\mathrm{mL})$ and analyzed by means of the DietPro ${ }^{\circledR}$ software, version $4.0^{16}$. It was calculated the means of energy $(\mathrm{kcal})$, carbohydrates, proteins and lipids. Macronutrients were evaluated in grams and percentage of energy.

The levels of DR, DD and $\mathrm{H}$ were assessed by the Three Factor Eating Questionnaire (TFEQ) ${ }^{5}$. Depending on the scores obtained after applying the questionnaire, the levels of $D R, D D$ and $H$ were classified respectively as low: $0-5$, $0-9$ and $0-4$; moderate: $6-9,10-12,5-7$; or high: $\geq 10, \geq 13$, $\geq 8$.

Anthropometric, body composition and food intake variables, as well as the DR, DD and $\mathrm{H}$ scores were expressed as means and standard deviations. The Kolmogorov-Smirnov and Lilliefors tests were used to assess the adherence to the normal distribution of variables. The means of all variables were compared between normal and overweight by Student's t (parametric variables) or Mann-Whitney tests (nonparametric variables). Correlations between scores for $\mathrm{DR}, \mathrm{DD}$ and $\mathrm{H}$ and anthropometric, body composition and food intake variables were tested by the Pearson (parametric variables) or Spearman (nonparametric variables) correlation coefficients. For statistical analysis it was used the software Statistica ${ }^{\circledR}$, version $7.0^{17}$

The study protocol is in accordance with the Resolution 196/96 of the National Health Council (Brazil), which regulates research involving human beings, the World Medical Association and the Helsinki Declaration. It also had the approval of the Ethics Committee on Research with Human Beings of the Federal University of Vales do Jequitinhonha and Mucuri (Resolution 036/2010). Moreover, all volunteers who agreed to participate signed a consent form.

\section{Results}

We evaluated 64 adult women. For the OW group, mean age was $28.7 \pm 6.8$ years, with a minimum of 21 and maximum of 40 years. At NW group, this mean was $29.6 \pm 5.7$ years, with a minimum of 21 and maximum of 40 years. There was no significant difference for age between groups $(P=.6620)$. The mean height was the same for both groups $(1.61 \pm 0.06$ $\mathrm{m})$.

At NW group, nearly half $(43.7 \%)$ of the women had completed high school, but for the OW group, only $1 / 4$ (25\%) achieved the same level of education. However, a significant proportion of both groups ( 37.5 for NW and $37,4 \%$ for OW) was attending or had completed undergraduate education. The consumption of alcoholic beverages was classified as absent for half of the volunteers in both groups, and the other half reported some level of consumption at social events ( 43.7 for NW and $50 \%$ for OW). The physical activity was reported to be more frequent in OW women (74.9\%). However, these activities were ranked as of low intensity $(56.2 \%)$ for most of them. There were also some reports of minor changes in weight in this group (31.2\%). For both NW and OW women, more than a half (68.7 and 87.5, respectively) reported family history of diseases related to inadequate nutrition.

The mean body weight for NW was lower than for OW women $(P<.05)$, with the same occurring for $\mathrm{BMI}, \% \mathrm{BF}$ and WC. In addition, the \% LM was higher for the NW ones. The OW group had a WC mean value compatible with metabolic risk $(\geq 80 \mathrm{~cm})$ whereas in the NW group, this value was considered normal (WHO, 1998). The mean of \% BF for the NW group was above $24 \%$ (average value), whereas in the OW group, this value represented the risk of disease 
Table 1 Distribution of anthropometric, body composition and food intake variables of normal weight $(\mathrm{n}=32)$ and overweight $(\mathrm{n}=32)$ women. Diamantina-MG, 2010

\begin{tabular}{lccc}
\hline Variables & \multicolumn{2}{c}{ Means \pm standard deviations } & $P$ value \\
\cline { 2 - 3 } & Normal weight & Overweight & $<.0001^{*}$ \\
\hline Weight $(\mathrm{kg})$ & $57.99 \pm 4.63$ & $73.77 \pm 6.41$ & $<.0001^{*}$ \\
IMC & $22.25 \pm 1.43$ & $28.52 \pm 1.38$ & $<.0001^{*}$ \\
WC $(\mathrm{cm})$ & $71.03 \pm 3.60$ & $85.33+6.08$ & $<.0001^{*}$ \\
$\% \mathrm{BF}$ & $28.01 \pm 3.13$ & $33.60 \pm 2.75$ & $<.0001^{*}$ \\
$\% \mathrm{LM}$ & $71.99 \pm 3.12$ & $66.40 \pm 2.75$ & .0291 \\
Calories (kcal) & $1657.23 \pm 462.10$ & $2427.39 \pm 1263.05$ & .5224 \\
$\%$ proteins (kcal) & $15.28 \pm 18.51$ & $16.07 \pm 54.26$ & .4654 \\
$\%$ lipids (kcal) & $44.75 \pm 19.43$ & $33.34 \pm 58.09$ & .3251 \\
$\%$ carbohydrates (kcal) & $55.37 \pm 75.68$ & $52.78 \pm 159.90$ & .0154 \\
Proteins (g) & $61.95 \pm 3.40$ & $98.76 \pm 3.47$ & .0114 \\
Lipids (g) & $54.18 \pm 61.44$ & $95.42 \pm 5.70$ & .0475 \\
Carbohydrates (g) & $226.66 \pm 8.03$ & $304.78 \pm 6.51$ & \\
\hline *Values considered to be significant. & & &
\end{tabular}

*Values considered to be significant.

Table 2 Distribution of scores for dietary restriction (DR), dietary disinhibition (DD) and hunger $(H)$ in normal weight $(n=32)$ and overweight $(\mathrm{n}=32)$ women. Diamantina-MG, 2010

\begin{tabular}{lllllll}
\hline Variables & \multicolumn{5}{l}{ Scores } \\
\cline { 2 - 7 } & \multicolumn{7}{l}{ Normal weight } & \multicolumn{5}{l}{ Overweight } \\
\cline { 2 - 7 } & Low & Medium & High & Low & Medium & High \\
\hline DR & $10(31.2)$ & $14(43.7)$ & $8(25.0)$ & $2(6.2)$ & $14(43.7)$ & $16(50.0)$ \\
DD & $31(93.7)$ & $1(6.2)$ & 0 & $10(31.2)$ & $20(62.5)$ & $2(6.2)$ \\
H & $22(68.7)$ & $6(18.7)$ & $4(12.5)$ & $8(25.0)$ & $12(37.5)$ & $12(37.5)$ \\
\hline
\end{tabular}

Scores are expressed as absolute frequencies (relative frequencies, \%). Scores for DR, DD and H were considered: low: 0-5, 0-9 and 0-4; moderate: 6-9, 10-12, 5-7; high: $\geq 10, \geq 13$, and $\geq 8$, respectively.

associated with obesity ( $\geq 32 \%$ ), as defined for Lohman et $\mathrm{al}^{18}$ (table 1).

The mean values of daily energy (kcal/day) and carbohydrates, proteins and lipids (g/day) in the OW women were higher than those at NW $(P<.05)$. There was no significant difference between groups regarding the percentage of energy from macronutrients (table 1).

About half of the OW women showed a high level of DR, whereas in the NW ones, it was observed just 1/4. More than $90 \%$ of the NW women showed low DD. In addition, none of them showed high levels. In the OW group, more than a half presented a medium level of DD. The level of $\mathrm{H}$ was classified as low for $1 / 4$ in the OW group, and for more than a half in the NW group (table 2).

The mean scores of DR, DD and hunger were significantly higher in the OW group. The mean DR scores in both groups were classified as moderate level, being the score for OW, closer to high level. The NW mean score for DD was classified as low level, whereas in the OW, this score matched the moderate level. For $\mathrm{H}$, both scores (NW and $\mathrm{OW}$ ), were also moderate. However, once again, this score in OW tended to be high (table 3 ).
Table 3 Scores for dietary restriction (DR), dietary disinhibition $(D D)$ and hunger $(H)$ in normal weight $(n=32)$ and overweight $(\mathrm{n}=32)$ women. Diamantina-MG, 2010

\begin{tabular}{lllr}
\hline Variables & Scores & \multicolumn{2}{c}{$P$ value } \\
\hline & Normal weight & Overweight \\
\hline DR & $7.56 \pm 2.73$ & $9.56 \pm 2.36$ & .0345 \\
DD & $5.25 \pm 2.38$ & $9.81 \pm 3.23$ & $<.0001$ \\
H & $4.69 \pm 2.24$ & $7.19 \pm 3.21$ & .0159 \\
\hline
\end{tabular}

Scores were expressed as mean \pm standard deviation.

There was no significant correlation among all variables for the NW group. There was a positive correlation between the scores of hunger and caloric intake $(r=.5641 ; P=.023)$, protein $(r=.5570 ; P=.025)$, carbohydrate $(r=.6074 ; P=.013)$ or lipids in absolute values $(r=.4981 ; P=.050)$ in the OW group. There was no correlation among all other variables tested for this group. 


\section{Discussion}

The groups were relatively homogeneous in terms of age, educational level, alcohol consumption and nutritionrelated diseases in the family. Regarding physical activity, although most of the women from OW group had reported some practice, which was referred to as light physical activity such as domestic working, short walks, office working, and some similar activities. Thus, it can be inferred that overweight women were more concerned with physical activity, but these activities are insufficient to help them to control body weight. In addition, these women reported less change in body weight, which corroborate this finding.

This information, associated with the higher energy intake in the OW group, is consistent with the highest intake of carbohydrates, proteins and lipids in absolute values. It also supports the highest BMI for this group, as well as, \% BF and WC. According to Stefater and Seeley ${ }^{19}$, the size of fat mass is controlled by a complex neuroendocrine system that works to adjust energy intake relative to expenditure. However, when caloric intake exceeds the expenditure in a persistent way, the positive energy balance causes changes in this system that ends with fat mass accumulation. Thus, it can be inferred that the higher energy intake in the OW women associated with low physical activity level is reflected in a positive energy balance, promoting higher body weight and fat.

It is important to note that even with the higher energy and macronutrient intakes in absolute values for the OW group, there was no difference between the percentages of energy from macronutrients, which is consistent with the findings of Hirvonen et $\mathrm{al}^{20}$. These authors state that even when there are significant differences in the total energy intake, the energy proportion from macronutrients do not change.

In the present study, we found an eating behavior, measured by DR, DD and $\mathrm{H}$, compatible with the BMI, body composition and caloric intake profile of in both groups, especially in the OW. Moderate or high DR levels were more prevalent in this group, which means these women restrict more their food intake in order to prevent weight gain or to promote weight loss. Indeed, DR has been used to explain the common observation that overweight or obese persons intend to diet to lose weight.

These women also presented scores for DD that, most of all, imply a behaviour characterized by the tendency to overeat in response to different stimuli, losing their selfcontrol of eating. DD can occur, for example, when an individual is exposed to a wide range of palatable foods or under emotional stress ${ }^{6}$. In this situation, they can eat more than that ones that have low DD. In addition, most of OW women also presented scores of moderate or high levels of $\mathrm{H}$, which means these women are more susceptible to eat in response to perceived physiological symptoms that signal the need for food.

On the other hand, Drapeau et $\mathrm{al}^{4}$ and Bellisle et $\mathrm{al}^{12}$ reported that neither DR nor $\mathrm{H}$ hunger has been consistently associated with BMI or changes in body weight. In contrast, these same authors also reported strong associations for DD. Indeed, this kind of behaviour has been strongly associated with weight gain over time and with obesity in adulthood by several studies, 12,21-24. In the present study, it was found a positive correlation between the scores of $\mathrm{H}$ and total energy (kcal/day) or macronutrient (g/day) intake, only in the OW group. Provencher et $\mathrm{al}^{23}$ also found a positive correlation between $\mathrm{H}$ and these variables in adult men and women. These authors also found positive correlations for DD and BMI, which were not observed in the present study. This can be explained because DR is considered as a multidimensional construct, including a history of dieting, current dieting and degree of sustained weight loss ${ }^{25}$. Also, Drapeau et $\mathrm{al}^{4}$ showed that few changes in eating behaviour were associated with changes in body weight or energy intake during six years in adults of both sexes, interestingly; those with high scores of DD had undergone little change in body weight during this period.

All these findings are consistent with several published reports that link higher DR followed by higher $\mathrm{DD}$ and $\mathrm{H}$ levels in individuals who wish to control body weight $3,6,7,23,26,27$. Also, cross-sectional studies reinforce that there are little independent effects of DR or DD or $\mathrm{H}$; but their interactions determine the effects on weight gain ${ }^{3}$. Dykes et $\mathrm{al}^{7}$ postulated that a high level of dietary restrained is less useful as a way to control body weight, when accompanied by a high level of dietary disinhibition. Similarly, when high scores of DD compete with high scores of $\mathrm{H}$, higher values of BMI are observed ${ }^{7,23,28}$.

These facts are extremely important when considering strategies to control body weight. Hill et $\mathrm{al}^{29}$ argue that given the current environment (obesogenic), cognitive control of food is needed to control weight gain. Therefore, the most effective way for weight control would be high DR with low DD and low $\mathrm{H}$.

In conclusion, the eating behaviour profile of OW women is consistent with their body weight and fat, despite the lack of association of DD with these parameters in both OW and NW. Thus, strategies for adaptations in cognitive control of food intake may become useful tools in controlling body weight.

\section{Conflict of interests}

The authors declare no conflicts of interests.

\section{References}

1. Fujimoto WY, Bergstron RW, Boiko EJ, Chen KW, Leonetti DL, Newell-Morris L, et al. Visceral adiposity and incident coronary heart disease in Japanese-American men. Diabetes Care. 1999;22:1808-12.

2. Rideout CA, Barr SI. "Restrained Eating" vs "Trying to Lose Weight": How are they associated with body weight and tendency to overeat among postmenopausal women? J Am Diet Assoc. 2009;109:890-93.

3. Hays NP, Bathalon GP, Mccrory MA, Roubenoff R, Lipman R, Roberts $\mathrm{SB}$. Eating behavior correlates of adult weight gain and obesity in healthy women aged 55-65 y. Am J Clin Nutr. 2002;75:476-83

4. Drapeau V, Provencher V, Lemieux S, Després JP, Bouchard C, Tremblay A. Do 6-y changes in eating behavior predict changes 
in body weight? Results from the Québec Family Study. Int $J$ Obes. 2003;27:808-14.

5. Stunkard AJ, Messick S. The three-factor eating questionnaire to measure dietary restraint, disinhibition and hunger. J Psychosom Res. 1985;29:71-83.

6. Hays NP, Roberts SB. Aspects of eating behaviors "disinhibition" and "restraint" are related to weight gain and BMI in women. Obesity. 2008;16:52-8.

7. Dykes J, Brunner EJ, Martikainen PT, Wardle J. Socioeconomic gradient in body size and obesity among women: the role of dietary restraint, disinhibition and hunger in the Whitehall II study. Int J Obes. 2004;28:262-8.

8. Cools J, Schotte DE, Mcnally RJ. Emotional arousal and overeating in restrained eaters. J Abnorm Psychol. 1992;101: 348-51.

9. Wardle J, Steptoe A, Oliver G, Lipsey Z. Stress, dietary restraint and food intake. J Psychosom Res. 2000;48:195-202.

10. Flint KMG, Van Walleghen EL, Kealey EH, Vonkaenel S, Bessesen DH, Davy BM. Differences in eating behaviors between nonobese, weight stable young and older adults. Eat Behav. 2008;9:3705.

11. Siegel JM, Yancey AK, Mccarthy WJ. Overweight and depressive symptoms among African-American women. Prev Med. 2000;31:232-40.

12. Bellisle F, Clément K, Le Barzic M, Le Gall A, Guy-Grand B, Basdevant $A$. The eating inventory and body adiposity from leanness to massive obesity: a study of 2509 adults. Obesity. 2004;12:2023-30.

13. Obesity: preventing and managing the global epidemic. Report of a WHO Consultation on Obesity. WHO/NUT/NCD/981. Geneva: WHO; 1998.

14. Lukaski HC, Bolonchuk WW, Hall CB, Siders WA. Validation of tretapolar bioelectrical impedance method to assess human body composition. J Appl Physiol. 1986;60:1327-32.

15. Willett W, Stampfer M. Implications of total energy intake for epidemiological analyses. In: Willett W. Nutritional epidemiology. 2nd ed. New York: Oxford University Press; 1998. p. 514.

16. AS Sistemas. DietPro ${ }^{\circledR}$ - Sistema de suporte à avaliação nutricional e cálculo de dietas. Software: Version 4.0. 2003.
17. Statsoft Inc. Statistica ${ }^{\oplus}$. Data analysis software. Software: Version 7.0. 2004.

18. Lohman TG, Roche AF, Martorell R. Anthropometric standardization reference manual. Champaign: Human Kinetics Books; 1988. p. 177.

19. Stefater MA, Seeley RJ. Central nervous system nutrient signaling: The regulation of energy balance and the future of dietary therapies. Annu Rev Nutr. 2010;30:219-35.

20. Hirvonen T, Mannisto S, Roos E, Pietinen P. Increasing prevalence of underreporting does not necessarily distort dietary surveys. Eur J Clin Nutr. 1997;51:297-301.

21. Lawson OJ, Williamson DA, Champagne CM, Delany JP, Brooks ER, Howat PM, et al. The association of body weight, dietary intake, and energy expenditure with dietary restraint and disinhibition. Obesity. 1995;3:153-61.

22. Williamson DA, Lawson OJ, Brooks ER, Wozniak PJ, Ryan DH, George A, et al. Association of body mass with dietary restraint and disinhibition. Appetite. 1995;25:31-41.

23. Provencher V, Drapeau V, Tremblay A, Després JP, Lemieux $S$. Eating behaviors and indexes of body composition in men and women from the Québec family study. Obesity. 2003;11:78392.

24. Savage JS, Hoffman L, Birch LL. Dieting, restraint, and disinhibition predict women's weight change over 6 y. Am J Clin Nutr. 2009;90:33-40.

25. Lowe MR. The effects of dieting on eating behavior. Psychol Bull. 1993;114:100-21.

26. Kristensen ST. Social and cultural perspectives on hunger, appetite and satiety. Eur J Clin Nutr. 2000;54:473-8.

27. Provencher V, Bégin C, Piché ME, Bergeron J, Corneau L, Weisnagel SJ, et al. Disinhibition, as assessed by the three-factor eating questionnaire, is inversely related to psychological wellbeing in postmenopausal women. Int J Obes. 2007;31:315-20.

28. Boschi V, lorio D, Margiotta N, D'orsi P, Falconi C. The threefactor eating questionnaire in the evaluation of eating behavior in subjects seeking participation in a dietotherapy programme. Ann Nutr Metab. 2001;45:72-7.

29. Hill JO, Wyatt HR, Reed GW, Peters JC. Obesity and the environment: where do we go from here? Science. 2003;299: 853-5. 